\title{
Detoxification and stress response genes expressed in a western North American bumble bee, Bombus huntii (Hymenoptera: Apidae)
}

\author{
Junhuan $\mathrm{Xu}^{1}$, James $\mathrm{P}$ Strange ${ }^{2}$, Dennis L Welker ${ }^{1}$ and Rosalind $\mathrm{R}$ James $^{2^{*}}$
}

\begin{abstract}
Background: The Hunt bumble bee (Bombus huntii Greene, Hymenoptera: Apidae) is a holometabolous, social insect important as a pollinator in natural and agricultural ecosystems in western North America. Bumble bees spend a significant amount of time foraging on a wide variety of flowering plants, and this activity exposes them to both plant toxins and pesticides, posing a threat to individual and colony survival. Little is known about what detoxification pathways are active in bumble bees, how the expression of detoxification genes changes across life stages, or how the number of detoxification genes expressed in B. huntii compares to other insects.

Results: We found B. huntii expressed at least 584 genes associated with detoxification and stress responses. The expression levels of some of these genes, such as those encoding the cytochrome P450s, glutathione S-transferases (GSTs) and glycosidases, vary among different life stages to a greater extent than do other genes. We also found that the number of P450s, GSTs and esterase genes expressed by B. huntii is similar to the number of these genes found in the genomes of other bees, namely Bombus terrestris, Bombus impatiens, Apis mellifera and Megachile rotundata, but many fewer than are found in the fly Drosophila melanogaster.

Conclusions: Bombus huntii has transcripts for a large number of detoxification and stress related proteins, including oxidation and reduction enzymes, conjugation enzymes, hydrolytic enzymes, ABC transporters, cadherins, and heat shock proteins. The diversity of genes expressed within some detoxification pathways varies among the life stages and castes, and we typically identified more genes in the adult females than in larvae, pupae, or adult males, for most pathways. Meanwhile, we found the numbers of detoxification and stress genes expressed by B. huntii to be more similar to other bees than to the fruit fly. The low number of detoxification genes, first noted in the honey bee, appears to be a common phenomenon among bees, and perhaps results from their symbiotic relationship with plants. Many flowering plants benefit from pollinators, and thus offer these insects rewards (such as nectar) rather than defensive plant toxins.
\end{abstract}

Keywords: Bees, Bombus huntii, Bumble bees, Detoxification genes, Transcriptome

\section{Background}

In addition to pesticide resistance, detoxification and stress responses are important adaptations that allow insects to overcome the chemical defenses of the plants and animals they feed on. Genes associated with these responses have been identified in many insects, including the mosquitoes Anopheles gambiae [1] and Aedes aegypti [2], the fruit fly Drosophila melanogaster [3], the

\footnotetext{
* Correspondence: Rosalind.James@ars.usda.gov

${ }^{2}$ USDA-ARS, Pollinating Insects Research Unit, Department of Biology, Utah

State University, Logan, UT 84322-5310, USA

Full list of author information is available at the end of the article
}

honey bee Apis mellifera [4], and the red flour beetle Tribolium castaneum [5]. During pollination activities, bees are exposed to toxic substances in the environment, such as pesticides, phytochemicals, microbial toxins, pollutants and other xenobiotics [6-8], but genomic analyses of the honey bee, $A$. mellifera, found fewer detoxification genes than are present in D. melanogaster and $A$. gambiae $[4,9]$. To determine if this phenomenon is common among bees or unique to the honey bee, we evaluated the expression of detoxification and stress related genes in a common western North American bumble bee, Bombus huntii (the Hunt bumble bee). Like $A$.

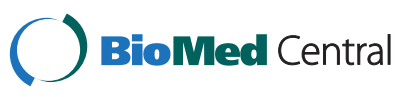

(c) 2013 Xu et al.; licensee BioMed Central Ltd. This is an open access article distributed under the terms of the Creative Commons Attribution License (http://creativecommons.org/licenses/by/2.0), which permits unrestricted use, distribution, and reproduction in any medium, provided the original work is properly cited. 
mellifera, B. huntii is a social insect with a diet based on pollen and nectar from a broad array of plants, so environmental exposures to xenobiotics should be similar. In addition, bumble bee susceptibility to pesticides has been found to be similar to that of $A$. mellifera [10].

Generally, stress responses and the detoxification of xenobiotics includes three major and interrelated pathways (Figure 1): oxidation-reduction, conjugation, and hydrolysis [11,12]. Oxidation-reduction enzymes include alcohol dehydrogenases, aldehyde dehydrogenases, cytochrome P450s, hydroxylases and peroxidases. Many cytochrome P450s are important enzymes for catalyzing oxidation-reduction reactions, and they are probably important for pesticide detoxification in A. mellifera [13]; however, reactive oxygen species (ROS), such as hydrogen peroxide, hydroxyl radicals, and superoxides, are typical by-products of these reactions. These ROS can be toxic in themselves, but are degraded by antioxidants, facilitated by other oxidation/reduction enzymes such as $\mathrm{CuZn}$ superoxide dismutases, catalases and peroxidases (Figure 1). In addition to the detoxification of insecticides and other xenobiotics, many of the oxidation/ reduction enzymes are also involved in the normal physiological functioning of insects. For example, cytochrome P450s are also involved in the production of pheromones, ecdysteroids and juvenile hormones [14-16], and many of the enzymes that breakdown ROS are associated with breaking down by-products from metabolism.

The products of oxidation/reduction may be further degraded through conjugation. Conjugation is the process by which sugars, amino acids, or glutathione are transferred to a carrier compound for movement out of the cell. A host of conjugation enzymes catalyze these reactions [17] (Figure 1). Particularly important in insecticide detoxification are members of the Glutathione S-transferases enzyme (GST) superfamily which catalyze the conjugation of oxidized lipids and exogenous toxins, such as pyrethroid and organophosphate pesticides [18-20] (Figure 1). GSTs are also involved in other functions, such as intracellular transport and the biosynthesis of hormones [21].

Detoxification is also carried out via hydrolysis, which transfers a hydrogen atom from water to the substrate compound, and these reactions are facilitated by hydrolytic enzymes [12] (Figure 1). For example, carboxyl esterases catalyze the hydrolysis of esters into an acid and an alcohol and are important in the degradation of pyrethroids and organophosphate insecticides [22]. In addition to these three pathways, other pathways may be invoked, such as those that involve ATP-binding cassette transporters (ABC transporters) [11], cadherins, or heatshock proteins.

Like all bumble bees, the life stages and castes of $B$. huntii vary considerably in morphology, behavior and activity, and so could be expected to differ in their expression of detoxification and stress related genes. As with all Hymenoptera, bumble bees have a haplodiploid sex determination, where males are produced from unfertilized, haploid eggs and females from fertilized, diploid eggs [23]. Bumble bees live in annual, eusocial colonies founded by a single queen whose daughters form a female worker caste that provides foraging, brood care and nest maintenance [24]. A colony begins when a

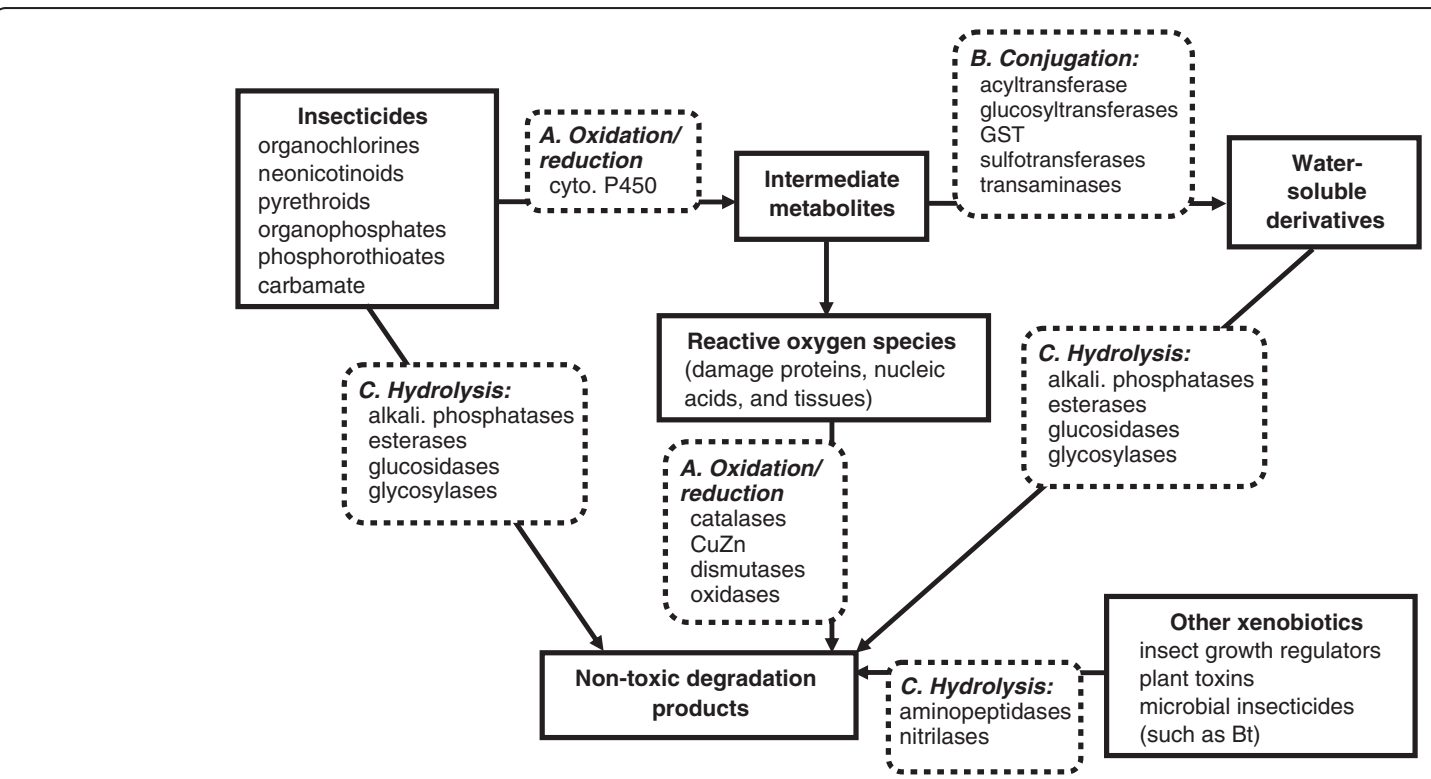

Figure 1 Typical detoxification pathways known for insects. Solid boxes indicate chemical compounds from the environment or as a result of metabolic processes. Dashed-line boxes indicate the three detoxification pathways that this paper focuses on. 
solitary overwintering queen emerges from hibernation, finds a suitable nesting site, provisions the nest with pollen and nectar, and commences laying eggs. The eggs hatch and larvae are fed nectar and pollen by the queen. In the fourth instar, the larvae begin to spin silk cocoons in which they pupate. The new adult bees emerge from their cells by chewing out of the cocoon, and these female workers then take over the responsibilities of brood care and foraging as the nest grows. Near the end of the summer, the next generation of reproductive adults is produced and the colony senesces. The new queens fly from the colony to mate with males and then diapause as solitary individuals in a suitable location for the winter, whereas workers, males and the colony's original queen do not survive the winter.

Our goal was to construct a transcriptome of the detoxification and stress response genes expressed in B. huntii. However, due to the complex life cycle of bumble bees, it is possible that not all the relevant genes are expressed in a single caste or life stage. To identify a fuller spectrum of genes expressed in $B$. huntii, messenger RNA (mRNA) was extracted from eggs, early instar larvae, late instar larvae, pupae, adult workers, adult males, an egglaying queen, and a diapausing queen. The corresponding cDNA was sequenced using pyrosequencing, and genes associated with detoxification and stress response were identified. We also compared the number of cytochrome P450, GST and carboxylesterase genes found in B. huntii (acrosss all life stages) to those found in the fly $D$. melanogaster, and those found in other bees where annotated genomes are available, namely $B$. terrestris, B. impatiens, A. mellifera, and M. rotundata, to evaluate whether the low number of detoxification genes found in A. mellifera [4] is unique to that bee, or more common among bees in general.

\section{Results}

An overview of detoxification and stress response genes in $B$. huntii

We developed a cDNA database of 102,778 contigs and singletons using pyrosequencing of mRNA extracted from eggs, larvae, pupae, adult workers, adult males, an egglaying queen, and a diapausing queen of B. huntii. Gene expression data were examined two ways: the number of different genes detected within a class of detoxification genes (the gene diversity), and the number of transcripts of a particular gene or class of genes (the expression level). The total gene diversity within all the detoxification and stress response-related genes expressed in B. huntii was approximately 584 genes (Additional file 1: Table S1), after we removed sequences with high similarity to microorganisms and plants. Of the original detoxification and stress-related gene sequences we identified in the samples, $13.8 \%$ were bacterial, $12.4 \%$ were similar to known plant sequences and $3.6 \%$ were similar to known fungal sequences. These were all removed. Among the remaining genes, we identified genes associated with oxidation-reduction, conjugation, and hydrolytic enzymes, as well as some other detoxification and stress responses (Additional file 1: Table S1, Tables 1 and 2). The genes for enzymes in each of these four groups were expressed differently in the various life stages and castes, with some expressed in multiple stages and others expressed in only one or two (Tables 1 and 2).

We found 202 genes associated with oxioreductases. Most of these were expressed across the majority of the life stages, but adult females had the greatest diversity of expressed gene types in this category (Table 2).

Of the 109 conjugation-enzyme related genes we identified, GSTs, glycosyltransferases, methyltransferases and aminotransferases (transaminases) were expressed in all life stages. The genes coding for acetyltransferases, acyltransferases, CoA transferases, formyltransferases, and phosphotransferases were also expressed in different life stages, but abundantly in adult females (Figures 2 and 3). Genes encoding sulfotransferases were expressed only in the diapausing queen (Figures 2 and 3).

We detected a total of 143 genes for hydrolytic enzymes, across all castes and life stages (Tables 1 and 2), but the greatest diversity of expressed gene type was again found in the adult females (Table 2).

In addition to the genes in these three major groups, we found 130 other genes encoding proteins that potentially have a detoxification or stress response function, such as ABC transporters, cadherins, heat shock proteins, isomerases and lyases (Additional file 1: Table S1). Late instar larvae, pupae and adult males had the lowest diversity of these genes (Tables 1 and 2).

\section{Gene expression among the different life stages of $B$. huntii}

The goal of this project was to survey detoxification and stress related genes in $B$. huntii. To do this, we used about 1000 eggs, 20-50 bees for the immature stages (see Methods), and one or two bees for the adult stages, and then pooled samples within each life stage for the 454 sequencing. Our sampling, which was not truly replicated within each life stage, provides some preliminary information on the expression levels among the different life stages and castes, but no statistical comparisons could be made. Among the immatures, the oxidoreductases were well expressed in the larvae, especially the late instar larvae (Figure 2). Within the conjugation enzyme group, the GSTs were highly expressed in the immatures, especially the pupae, but not the eggs (Figure 2). Genes associated with hydrolytic enzymes were also highly expressed in the immatures, especially the nitrilases, and again, particularly in the late instar larvae sample (Figure 2). 
Table 1 Putative functions for the detoxification genes expressed in different life stages of Bombus huntii, based on the function assigned when the gene was first isolated

\begin{tabular}{|c|c|c|c|c|}
\hline Enzymes & Putative functions & Taxon of identified gene & Reference & $\begin{array}{l}\text { Bombus } \\
\text { huntii life } \\
\text { stage/caste }\end{array}$ \\
\hline
\end{tabular}

\section{Oxidation and reduction enzymes}

Aldehyde

dehydrogenases

Alcohol

dehydrogenases

Catalases

Cytochrome P450s

Dehalogenases

Hydroxylases

Oxidoreductases

Peroxidases

Superoxide

dismutases (SOD)

Thioredoxins/ glutaredoxins
Acetaldehyde detoxification

Interconversion of alcohols and aldehydes or ketones with the reduction of $\mathrm{NADH}$

Catalyze $\mathrm{H}_{2} \mathrm{O}_{2}$ to $\mathrm{H}_{2} \mathrm{O}$ and $\mathrm{O}_{2}$

Detoxify xenobiotics by transferring $\mathrm{O}_{2}$ to a substrate and producing $\mathrm{H}_{2} \mathrm{O}_{2}, \mathrm{OH}^{-}, \mathrm{O}_{2}^{-}$

Remove halogen from haloacid compounds

Degrades toxic organic compounds and pesticides by introducing $-\mathrm{OH}$

\section{Detoxify gramine}

Catalyze $\mathrm{H}_{2} \mathrm{O}_{2}$ and organic hydroperoxides (OHPs)

Catalyze the dismutation of $\mathrm{O}_{2}^{-}$into $\mathrm{O}_{2}$ and $\mathrm{H}_{2} \mathrm{O}_{2}$

Detoxification of ROS

\section{Conjugation enzymes}

Acetyltransferases

Detoxify sulfadiazine and aromatic chemicals by transferring acetyl groups from acetyl-CoA to arylamines

Acyltransferase

Catalyze carboxylic acid group, such as benzoic, isovaleric, or acetylsalicylic acids

CoA transferases

Acetate detoxification

Formyltransferases

Formaldehyde detoxification

Glutathione S-

transferases (GST)

Detoxify endogenous compounds (peroxidised lipids) and exogenous toxins (pyrethroid and organophosphate) by catalyzing reduced glutathione

Glycosyltransferases

Glycosyltransfer to $\mathrm{OH}_{-}, \mathrm{NH}_{2}-$, $\mathrm{SH}-$, or $\mathrm{COOH}$ for detoxifying insecticides

Methyltransferases

Catalyze methylation reactions using S-adenosyl-L-methionine as a substrate for detoxification

Phosphotransferases

Sulfotransferases

Transaminases or aminotransferases

Detoxify insecticides such as DDT

Detoxify insecticides such as DDT

Detoxify 3-hydroxykynurenine and glyoxylate by catalyzing amino acid and a-keto acid

\begin{tabular}{|c|c|c|}
\hline Drosophila melanogaster & [25] & ii, iii, v, vi, vii \\
\hline D. melanogaster & {$[25]$} & all \\
\hline Anopheles gambiae & [26] & $\begin{array}{l}\text { i, ii, iii, vi, vii, } \\
\text { viii }\end{array}$ \\
\hline $\begin{array}{l}\text { D. melanogaster, A. gambiae, } \\
\text { Tyria jacobaeae, Culex } \\
\text { quinquefasciatus }\end{array}$ & {$[1,16,27,28]$} & all \\
\hline Sinorhizobium meliloti & [29] & iii, iv, vi, vii \\
\hline Chrysopogon zizanioides & {$[30]$} & ii-vii \\
\hline Sitobion avenae & [31] & all \\
\hline A. gambiae & [32] & all \\
\hline A. mellifera & {$[33,34]$} & all \\
\hline Saccharomyces cerevisiae & {$[35]$} & i, ii, vi, vii, viii \\
\hline
\end{tabular}

Legionella pneumophila, Homo [36,37] sapiens

i, ii, iii, v, vi, vii, viii

H. sapiens

Aspergillus nidulans

[39]

i, ii, iv, vi, vii, viii

Burkholderia fungorum

viii

Tenebrio molitor, Bombus ignites, Locusta migratoria manilensis

$\begin{array}{lll}\text { Bombyx mori } & {[17,42]} & \text { all } \\ \text { H. sapiens } & {[43]} & \text { all } \\ \text { Triatoma infestans } & {[44]} & \text { i, ii, vi, vii, viii } \\ \text { T. infestans } & {[44]} & \text { iii, vii } \\ \text { Aedes aegypti, D. melanogaster } & {[45]} & \text { ii-viii }\end{array}$

Lucilia cuprina, D.

[22] all

Acetylcholine and carboxyl esterases

Detoxify pyrethroids and organophosphates by hydrolysis of acyl group or ester bonds

Acid/Alkaline phosphatases

Detoxify endotoxin and plant toxin

Amidases

Detoxify toxic amides or esters, or organophosphorus or carbamate pesticides

Aminopeptidases

Detoxify Bt Cry toxin, mycotoxin, organophosphonates, pyrethroid esters, microbial or botanical pesticides

Cyclohydrolase melanogaster

Danio rerio, Agriolimax agrestis $\quad[46,47] \quad$ ii, iii, vi, vii

Acromyrmex octospinosus

[48]

B. mori, Pseudoplusia

includens, E. coli

Drosophila spp.
[40]

i, ii, iii, vi, vii, viii

$[18,41] \quad$ all Hydrolysis of L-phenylalanine 
Table 1 Putative functions for the detoxification genes expressed in different life stages of Bombus huntii, based on the function assigned when the gene was first isolated (Continued)

\begin{tabular}{|c|c|c|c|c|}
\hline Glycosidases & $\begin{array}{l}\text { Hydrolyze sugar-containing compounds such as tannic acid and } \\
\text { gallic acid }\end{array}$ & Manduca sexta & [48] & $\begin{array}{l}\text { i, ii, iii, v, vi, vii, } \\
\text { viii }\end{array}$ \\
\hline Glycosylases & $\begin{array}{l}\text { Detoxify cytotoxic and cytostatic substances such as 5-methyl } \\
\text { group of a thymine residue, biodegrade saponins }\end{array}$ & $\begin{array}{l}\text { Phaeosphaeria nodorum, P. } \\
\text { avenaria f. sp. triticea }\end{array}$ & [51] & i, ii, vi, vii, viii \\
\hline Nitrilases & Detoxify HCN & Caenorhabditis elegans & [52] & i-vii \\
\hline Phosphodiesterase & $\begin{array}{l}\text { Break phosphodiester bond for hydrolysis of organophosphate } \\
\text { insecticides }\end{array}$ & E. coli & [53] & ii, iii, iv, vi, vii \\
\hline Phosphohydrolases & Detoxify cypermethrin and bifenthrin & Tribolium castaneum & [54] & ii, iii-viii \\
\hline \multicolumn{5}{|c|}{ Others with possible stress related functions } \\
\hline ABC transporters & Export conjugated toxins out of the cell & Drosophila spp. & [11] & vii, viii \\
\hline Cadherins & Resistance to Bt toxin (Cry1Ac) & Helicoverpa armigera & [55] & i, ii, vi, vii, viii \\
\hline Heat shock proteins & $\begin{array}{l}\text { Involved in folding and unfolding of proteins, detoxification of } \\
\text { pesticides and heavy metals }\end{array}$ & Chironomus tentans & [56] & all \\
\hline Isomerases & $\begin{array}{l}\text { Detoxify organophosphates by structural rearrangement of } \\
\text { isomers }\end{array}$ & E. coli & [16] & all \\
\hline Lyases & $\begin{array}{l}\text { Break various chemical bonds other than hydrolysis and oxidation } \\
\text { for detoxification }\end{array}$ & Zygaena transalpina & {$[57]$} & all \\
\hline
\end{tabular}

i-egg, ii-early instar larvae, iii-late instar larvae, iv-pupae, v-adult male, vi-adult worker, vii-diapausing queen, viii-egglaying queen, all-all stages.

Genes associated with oxidation and reduction were well expressed in all the adult stages. The egglaying queen had quite high expression levels of these genes, although not for all the genes (Figure 3). As with the immatures, GSTs were the most well expressed genes in the conjugation enzyme group. In contrast to the high GST expression in the immatures, the glycosidases in adults were the most expressed of the hydrolytic enzymes, particularly in the adult workers and the egglaying queen (Figure 3). Heat shock protein genes were well expressed in the eggs, the diapausing queen and the egglaying queen, while expression levels in the males was fairly low (Figure 4).

\section{Comparison of detoxification genes in B. huntii with other} insects

Gene diversity for detoxification and stress related genes in B. huntii was similar to, or lower than, that for the other bees (B. terrestris, B. impatiens, A. mellifera and $M$. rotundata), and generally a much lower gene diversity than D. melanogaster (Table 3). Drosophila melanogaster has many more P450s, acyltransferases, GSTs, and most of the hydrolases, than any of the bees. One exception is the nitrilases, for which we found a high diversity in $B$. huntii. The high nitrilase gene diversity does not occur in the other bees (Table 3). Our data was based on a transcriptome and may underrepresent the number of genes, relative to the number identified in the genomes of the other species included in this analysis.

We also compared some subgroups within the cytochrome P450s and GSTs. Within the cytochrome P450s, the CYP2 and mitochondrial P450 enzymes tend to have endogenous functions, while the CYP4 and CYP6 enzymes have detoxification functions. We found a similar number of CYP6 related genes among the six insects, however a greatly reduced number of CYP4 related

Table 2 The number of detoxification genes identified, as expressed in different life stages of Bombus huntii

\begin{tabular}{|c|c|c|c|c|c|}
\hline Stages & Oxidation-reduction genes & Conjugation genes & Hydrolysis genes & Other detoxification genes & Total \\
\hline Egg & 36 & 14 & 22 & 21 & 93 \\
\hline Early instars & 49 & 20 & 33 & 23 & 125 \\
\hline Late instars & 64 & 18 & 35 & 12 & 129 \\
\hline Pupa & 31 & 9 & 13 & 7 & 60 \\
\hline Adult male & 36 & 11 & 23 & 13 & 83 \\
\hline Adult worker & 87 & 40 & 59 & 60 & 246 \\
\hline Diapausing queen & 93 & 40 & 54 & 60 & 247 \\
\hline Egglaying queen & 68 & 30 & 36 & 47 & 181 \\
\hline All stages & 202 & 109 & 143 & 130 & 584 \\
\hline
\end{tabular}




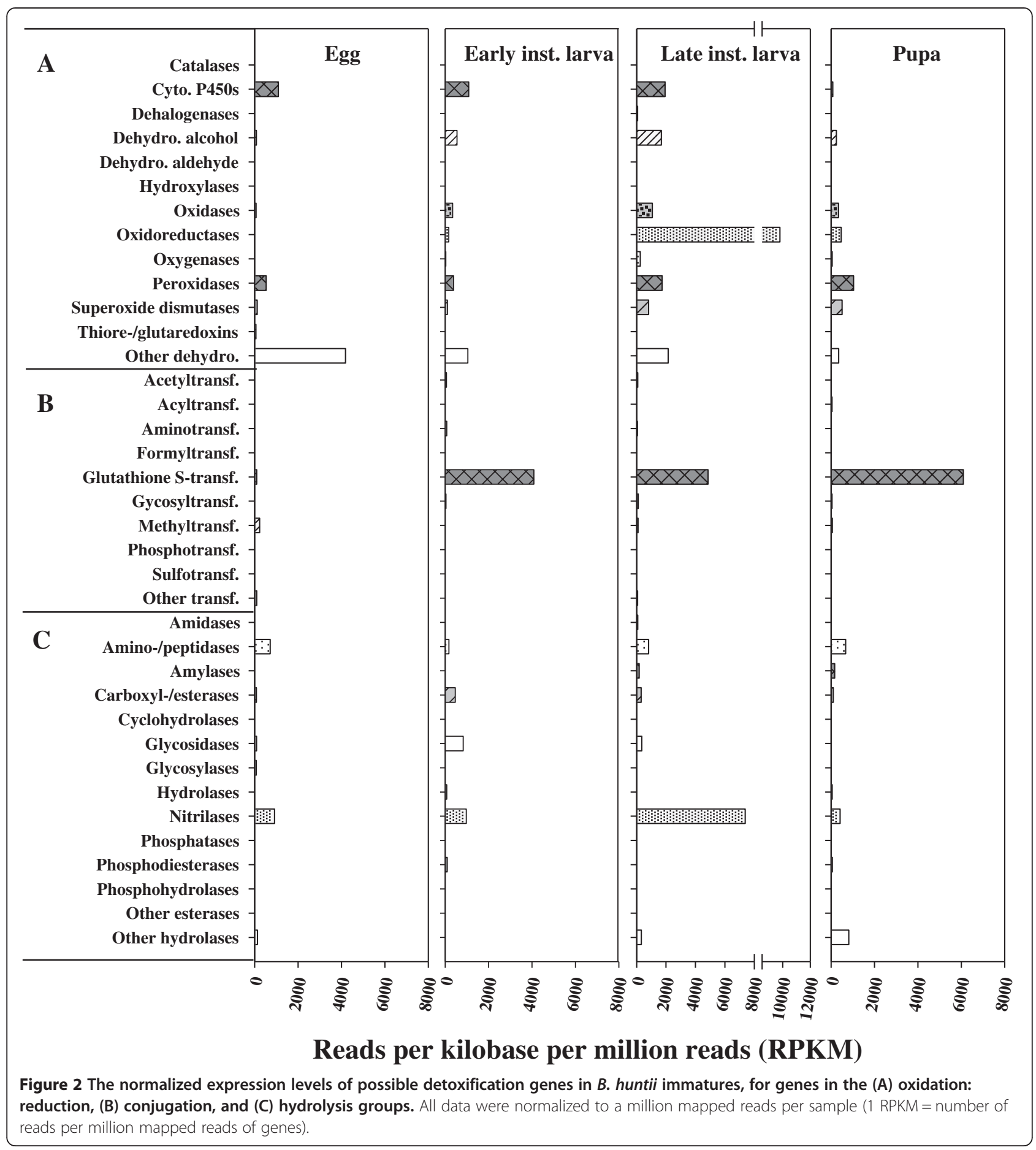

genes in the bees, relative to D. melanogaster (Table 3). The GSTs are composed of several sub-groups, but the sigma-GSTs and epsilon-GSTs comprise the main subgroups with detoxification functions. We found very few sigma-GSTs occurred in any of these insects; however, fewer epsilon-GSTs occurred in the bees than D. melanogaster (Table 3).

\section{Discussion}

Female adults (workers and queens) had the greatest diversity and gene expression levels among the detoxification and stress related genes we identified in B. huntii. Female adults expressed high levels of putative detoxification genes, while adult males and pupae had relatively lower expression levels of these genes. The low diversity 


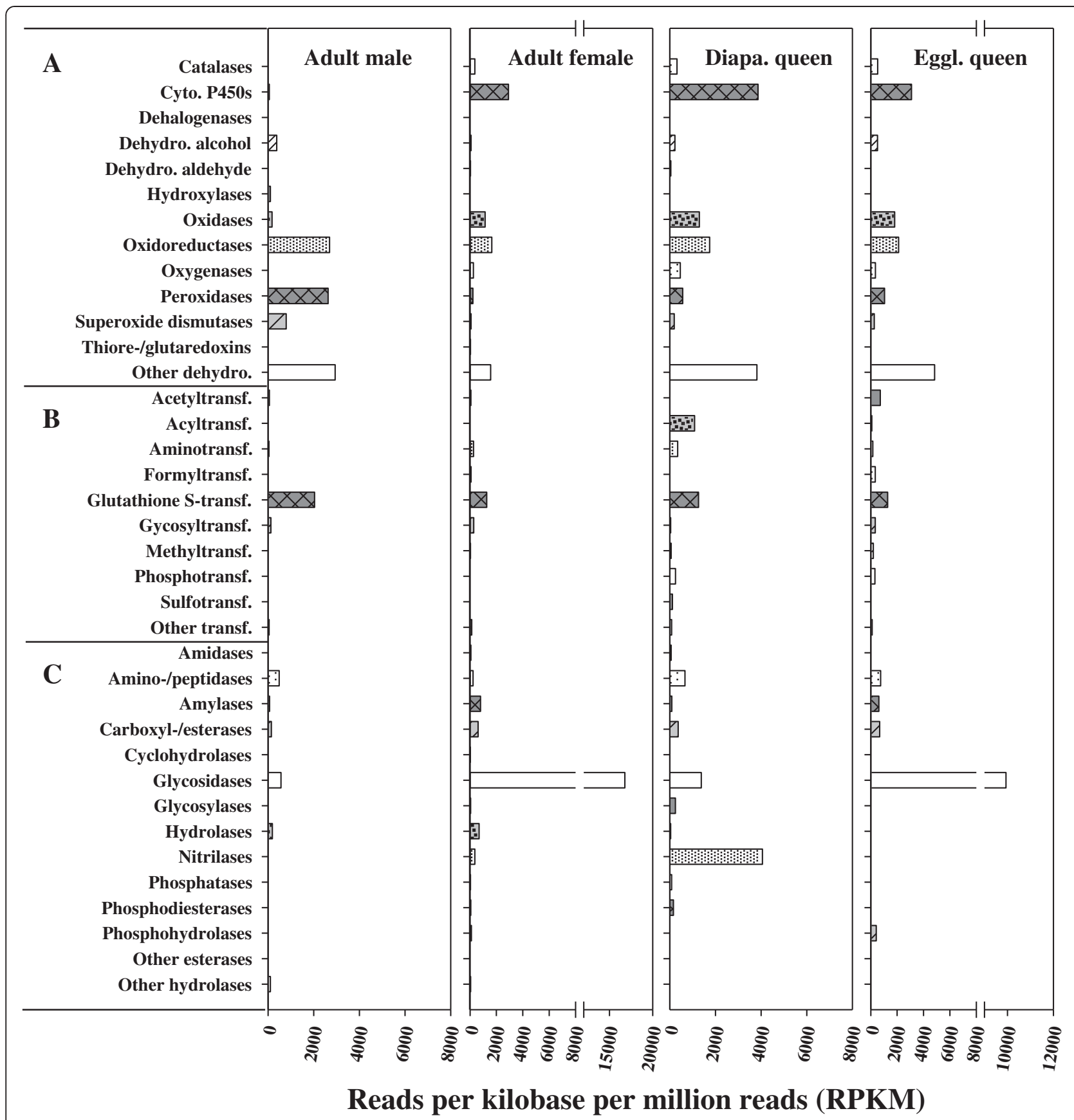

Figure 3 The normalized expression levels of possible detoxification genes in B. huntii adults, for genes in the (A) oxidation: reduction, (B) conjugation, and (C) hydrolysis groups. All data were normalized to a million mapped reads per sample (1 RPKM = number of reads per million mapped reads of genes).

and expression levels in males may in part be associated with haploidy, as was demonstrated in the stingless bee Melipona quadrifasciata [58]. Behaviors associated with the different bumble bee castes may also affect gene expression. Male activities are all related to feeding themselves and mating; whereas, both workers and queens have more complex behaviors, often with high energy demands (e.g. foraging, brood care, and egglaying).
Increases in foraging and feeding activity directly increase the risk of exposure to environmental pollutants; furthermore, increased energy demands have been shown to increase consumption rates and the formation of metabolic by-products in A. mellifera [59]. An actively laying queen may not forage after the first batch of brood matures, but she does have high metabolic demands for egglaying, policing the nest to keep workers 


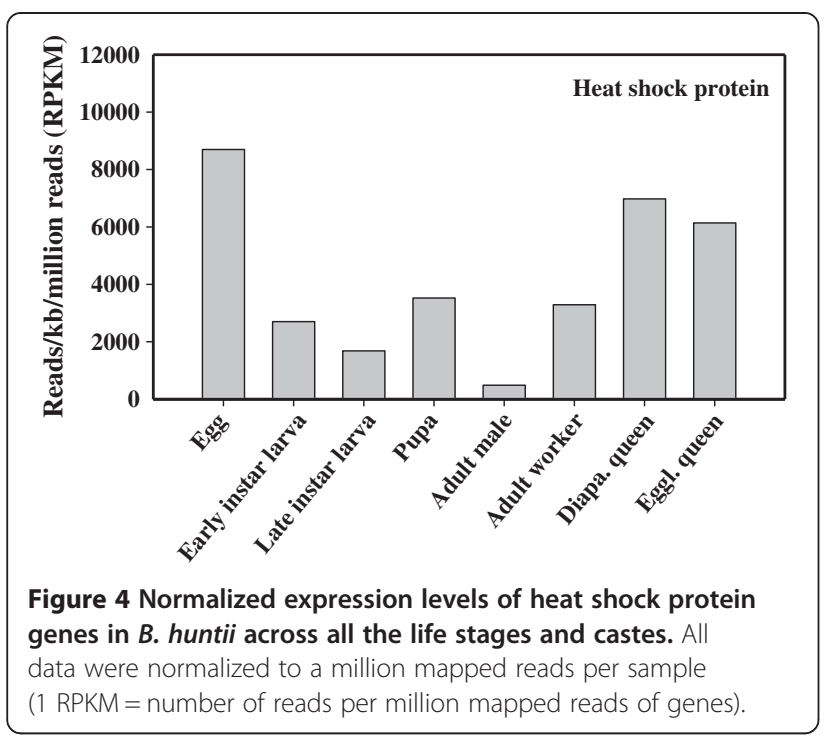

from becoming egg layers, and incubating the brood. And, indeed, the diversity and expression of potential detoxification genes is relatively high in queens and workers.

Additionally, detoxification activity could be affected by variations in hormone levels and the complex morphological changes that occur in holometabolous insects. Changes of hormone levels during insect development are well quantified in Drosophila, with the steroid hormone ecdysone showing peaks during the transition from larva to pupa [60]. Metabolic activity also varies between life stages; most notably it declines during diapause, a dormant state during which respiration is very low. Thus, the fact that detoxification genes are more highly expressed in an egglaying than a diapausing queen is not entirely surprising. Non-diapausing adults are more active than pupae, but pupae undergo a major metamorphosis, so the relative expression of detoxification and stress related genes is more difficult to predict, but is more likely to be the result of metabolic processes and not a result of xenobiotic exposure.

Some detoxification mechanisms may be required more during certain developmental stages, and some genes that we classified as potential detoxification genes may serve non-detoxification functions. For example, glycosidases are more highly expressed in queens and workers than in other stages. Glucosidase catalyzes the cleavage of individual glucosyl residues from various glyco-conjugates, a process involved in the breakdown of sugar-containing compounds during the digestion of pollen and nectar. GSTs also break down a variety of compounds produced during metabolism and digestion, such as partially digested lipids, in addition to their involvement in the detoxification of environmental toxins, plant allelochemicals, and organochlorine and organo- phosphate insecticides [18-20]. GST genes are expressed at high levels in $B$. huntii adults, pupae, and larvae, but at low levels in eggs, which may be related to either differences in metabolism or exposure to environmental toxins. For example, late instar bee larvae accumulate high levels of lipids $[61,62]$ and the high expression of GSTs in pupae may be related to the metabolism of these lipids during pupation. Similar results have been reported in other insects such as A. aegypti, Lucilia cuprina, and Tenebrio molitor, where the enzyme activities of GSTs were particularly high in the pupal stage [63]. In addition, some cytochrome P450s are involved in lipid metabolism, perhaps explaining why late instar larvae had higher expression levels of cytochrome P450s than early instar larvae.

Our gene analysis was based on a transcriptome, and as such, might underrepresent the number of detoxification genes found in the genome. However, we found similar numbers of genes to those found in the genomes of other bees. In addition, we used a large number of individuals for our transcriptome, and from across all the life stages of the bee. Thus, our transcriptome is probably a good library of the detoxification and stress related genes found in $B$. huntii. The fact that our bees were produced in culture on sugar syrup, rather than flower nectar, may have reduced the expression of some detoxification genes, such as has been found with honey bees [64]. However, we also fed our bees pollen collected by honey bees, and this likely provided a source of plant based phenolics and perhaps even traces of pesticides.

Due to the importance of detoxification capabilities during a bumble bee's life, one might expect $B$. huntii to have a genome rich in detoxification genes; however, like other bees such as $A$. mellifera, $B$. terrestris and B. impatiens, we found $B$. huntii to have relatively few P450s, GSTs and carboxylesterases/esterases, as compared to $D$. melanogaster. For example, the number of P450 CYP4 genes is quite high in $D$. melanogaster, relative to what we found in B. huntii. Bombus huntii also has fewer epsilon-GSTs genes in comparison to D. melanogaster, although we found a slightly higher number of sigmaGSTs in B. huntii and A. mellifera. Epsilon-GSTs are known to be involved in DDT (dichlorodiphenyltrichloroethane) resistance and the detoxification of xenobiotics. The high number of epsilon-GSTs in D. melanogaster must reflect either a greater evolutionary diversification of these genes in the fruit fly, a loss of some genes in the bees, or a combination of both. In any case, this could arise if flies tend to have a greater exposure to environmental toxins than do the bees. Sigma-GSTs are associated with the detoxification of lipid peroxidation products, and provide protection from oxidants produced by the aerobic metabolism of honey, pollen and nectar in the bees [9]. Thus, the slightly greater number 
Table 3 Comparison of the number of detoxification genes identified in Bombus huntii, in other bees, and in Drosophila melanogaster

\begin{tabular}{|c|c|c|c|c|c|c|}
\hline Putative function & $\begin{array}{l}\text { Bombus } \\
\text { huntii }\end{array}$ & $\begin{array}{l}\text { Bombus } \\
\text { terrestris }\end{array}$ & $\begin{array}{l}\text { Bombus } \\
\text { impatiens }\end{array}$ & $\begin{array}{l}\text { Apis } \\
\text { mellifera }\end{array}$ & $\begin{array}{l}\text { Megachile } \\
\text { rotundata }\end{array}$ & $\begin{array}{l}\text { Drosophila } \\
\text { melanogaster }\end{array}$ \\
\hline \multicolumn{7}{|c|}{ Oxidation and reduction enzymes } \\
\hline Aldehyde dehydrogenases & 5 & 5 & 5 & 6 & 18 & 23 \\
\hline Catalases & 2 & 1 & 2 & 6 & 5 & 3 \\
\hline Cytochrome P450 & 44 & 50 & 49 & 46 & 52 & 85 \\
\hline (CYP4) & (2) & (6) & (5) & (5) & (6) & (22) \\
\hline (CYP6) & $(18)$ & $(22)$ & (22) & (28) & (19) & (22) \\
\hline Glutaredoxins & 2 & 3 & 7 & 4 & 3 & 7 \\
\hline Peroxidases & 16 & 9 & 9 & 17 & 9 & 20 \\
\hline Superoxide dismutases & 2 & 4 & 6 & 5 & 8 & 6 \\
\hline \multicolumn{7}{|l|}{ Conjugation enzymes } \\
\hline Acyltransferases & 13 & 28 & 30 & 32 & 8 & 55 \\
\hline Glutathione S-transferases & 11 & 14 & 15 & 18 & 9 & 42 \\
\hline (Sigma-GSTs) & (3) & $(0 / ?)$ & $(0 / ?)$ & (4) & (1) & (1) \\
\hline (Epsilon-GSTs) & (0) & $(0 / ?)$ & $(0 / ?)$ & (0) & (0) & (10) \\
\hline Sulfotransferases & 2 & 17 & 16 & 17 & 5 & 15 \\
\hline $\begin{array}{l}\text { UDP- } \\
\text { glucuronosyltransferases }\end{array}$ & 2 & 6 & 8 & 2 & 2 & 7 \\
\hline \multicolumn{7}{|l|}{ Hydrolytic enzymes } \\
\hline Alkaline phosphatases & 1 & 3 & 4 & 3 & 2 & 16 \\
\hline Amidases & 2 & 4 & 8 & 4 & 7 & 12 \\
\hline Aminopeptidases & 12 & 19 & 26 & 24 & 27 & 41 \\
\hline Amylases & 2 & 1 & 1 & 2 & 2 & 15 \\
\hline Carboxylesterases/Esterases & 23 & 17 & 22 & 24 & 22 & 54 \\
\hline Glucosidases & 8 & 7 & 8 & 18 & 5 & 29 \\
\hline Glucuronidases & 1 & 1 & 1 & 1 & 2 & 4 \\
\hline Glycosylases & 3 & 2 & 5 & 7 & 6 & 5 \\
\hline Nitrilases & 25 & 1 & 2 & 3 & 2 & 2 \\
\hline
\end{tabular}

Note: The numbers of $B$. huntii and $M$. rotundata genes are transcriptome data from 454 pyrosequencing, except for $\mathrm{P} 450$ of $M$. rotundata which is genomic data. The numbers of B. terrestris, B. impatiens, A. mellifera, and D. melanogaster genes are from genomic data from the NCBI GenBank database (http://www.ncbi.nlm.nih.gov/ genome, accessed on September 25, 2013), and the numbers in brackets below P450 or GSTs are subgroups of P450 or GSTs.

of sigma-GSTs in bees also appears to reflect their ecological niche.

We found here that the low number of detoxification genes found in the A. mellifera genome [4] is a phenomenon common to many bees. We hypothesize that this phenomenon may have arose as a result of the symbiotic relationship between bees and flowering plants. Flowering plants often produce rewards (such as nectar) to attract bees and other pollinators. Furthermore, at least some plants have lower levels of plant defensive compounds in the pollen and nectar [8], and adding plant alkaloids to the nectar reduces pollinator activity on those flowers [65]. Thus, the detoxification abilities of bees may be less than the flies (and likely other insects as well) due to a lower level of exposure to plant defensive compounds, compounds that plants produce to defend themselves against herbivores not pollinators.

\section{Conclusions}

Using transcriptome analysis of all life stages, we found the Hunt bumble bee, $B$. huntii, to have the genetic potential to produce a large number of detoxification and stress related proteins, including oxidation and reduction enzymes, conjugation enzymes, hydrolytic enzymes, $\mathrm{ABC}$ transporters, cadherins, and heat shock proteins. The number of genes in these pathways was fewer than found in flies, such as D. melanogaster, and slightly lower than that found in the bumble bees $B$. terrestris and $B$. impatiens, the honey bee A. mellifera, and the solitary bee $M$. rotundata. However, a transcriptome may underestimate gene diversity, as compared to 
studies based on a genome. We also found that, in general, low levels of detoxification and stress related genes are expressed in pupae, adult males and larvae than in adult females. Workers and queens express high levels of P450s and glycosidases.

\section{Methods}

\section{Source of B. huntii}

Eight different stages of $B$. huntii were used in this analysis: eggs, early (2nd and 3rd) instar larvae, late (4th) instar larvae, pupae, adult workers, adult males, a diapausing queen, and an egglaying queen. All stages were collected from a nest cultured in the lab at the USDAARS Pollinating Insect Research Unit in Logan, UT, except for the diapausing queen, which was a sister of the egglaying queen and had been held in cold storage at $4^{\circ} \mathrm{C}$ for three months prior to collection for sequencing. The bees were reared according to Strange [66] and were started from queens that were raised and mated in the laboratory. The colony was fed on a diet of pollen collected from honey bee colonies and a 1:1:2 glucose:fructose:sucrose syrup solution. The eggs, larvae and pupae were removed from the colony and killed directly by immersion in RNAlater solution (Life Technologies, NY, USA), whereas the adult bees were first killed by immersion in liquid nitrogen and were then placed in vials of RNAlater solution. All bee tissues were submerged in approximately 5 volumes of RNAlater solution and kept at $4^{\circ} \mathrm{C}$ overnight to permeate the cells for stabilizing the RNA, the samples were then stored (about one month) at $-80^{\circ} \mathrm{C}$ until processed.

\section{Preparation of RNA}

For RNA isolation, about 1000 eggs, 50 2nd-3rd instar larvae, 20 4th instar larvae, 20 pupae, two adult males, two adult workers, one egglaying queen and one diapausing queen were removed from RNAlater and washed twice with nuclease free water and then transferred to a mortar and ground in liquid nitrogen to a fine powder. The total RNA was extracted by resuspending the ground powder into $20 \mathrm{ml}$ extraction buffer [100 mM NaCl, 2\% SDS, $50 \mathrm{mM}$ Tris- $\mathrm{HCl}$ (pH 9.0), $10 \mathrm{mM}$ EDTA (pH 8.0)] and $20 \mathrm{ml}$ phenol-chloroformisoamyl alcohol (IAA) (49.5:49.5:1, by volume) in a $50 \mathrm{ml}$ centrifuge tube. The solution was mixed and then centrifuged at $8,000 \mathrm{rpm}$ for $20 \mathrm{~min}$ at $4^{\circ} \mathrm{C}$. The aqueous phase was removed and placed in a clean centrifuge tube and an equal volume of phenol-chloroform-IAA (49.5:49.5:1) was added. The mixture was shaken and then centrifuged at $8,000 \mathrm{rpm}$ for $20 \mathrm{~min}$ at $4^{\circ} \mathrm{C}$. This organic extraction was repeated two more times. The RNA was precipitated with a $1 / 10$ volume of $3 \mathrm{M}$ sodium acetate ( $\mathrm{pH} 5.2$ ) and 2.5 volumes of $95 \%$ ethanol.
The RNA pellet was washed with $70 \%$ ethanol, dried for $5 \mathrm{~min}$, and resuspended in $400 \mu \mathrm{l}$ RNase-free water containing $1 \%$ diethylpyrocarbonate (DEPC). We repeated total RNA extraction once for each treatment.

Poly(A) + mRNAs were purified with an oligo(dT)-cellulose column through the binding, washing and elution steps. First, $1 \mathrm{ml}$ of total RNA solution (1 mg of RNA for each sample, except $\sim 200 \mu \mathrm{g}$ for eggs, this was half of the RNA from each extraction) was heated at $65^{\circ} \mathrm{C}$ for $5 \mathrm{~min}$, then cooled on ice for $5 \mathrm{~min}$, and $200 \mu \mathrm{l}$ sample buffer [ $3 \mathrm{M} \mathrm{NaCl}, 10 \mathrm{mM}$ Tris (pH 7.5), $1 \mathrm{mM}$ EDTA] was added. For the binding step, $8.8 \mathrm{ml}$ of binding solution $[0.5 \mathrm{M} \mathrm{NaCl}, 10 \mathrm{mM}$ Tris (pH 7.5), 0.5\% SDS, $0.1 \mathrm{mM}$ EDTA] was added to $1.2 \mathrm{ml}$ RNA sample, agitated for $30 \mathrm{~min}$ and then briefly centrifuged to remove the supernatant; all steps were repeated twice more. For the washing step, $10 \mathrm{ml}$ of high salt buffer $[0.5 \mathrm{M} \mathrm{NaCl}$, $10 \mathrm{mM}$ Tris (pH 7.5), $1 \mathrm{mM}$ EDTA] were added to the oligo(dT)-cellulose, which was then mixed by rotating $2 \mathrm{~min}$, followed by a brief centrifugation to remove the supernatant. The oligo(dT) was then suspended in $10 \mathrm{ml}$ of high salt buffer and transferred to a 20 ml-column (Bio-Rad, Hercules, CA, USA), washed with the high salt buffer twice, then washed another time with a low salt buffer $[0.5 \mathrm{M} \mathrm{NaCl}, 10 \mathrm{mM}$ Tris (pH 7.5), $1 \mathrm{mM}$ EDTA]. Pre-warmed $\left(65^{\circ} \mathrm{C}\right)$ elution buffer [10 mM Tris ( $\mathrm{pH} 7.5), 1 \mathrm{mM}$ EDTA] (3 ml) was added to the top of the oligo(dT)-cellulose for a third time, the suspension was collected, and mRNA was precipitated by adding $50 \mu \mathrm{l}$ of glycogen solution (20 $\mathrm{mg} / \mathrm{ml}), 1 / 10$ volume of $3 \mathrm{M} \mathrm{NaAc}$ ( $\mathrm{pH}$ 5.2), $7.5 \mathrm{ml}$ of $100 \%$ chilled ethanol, and stored overnight at $-20^{\circ} \mathrm{C}$ before being centrifuged. The mRNA pellet was washed with $70 \%$ ethanol and dried for $10 \mathrm{~min}$, and then dissolved in $80 \mu \mathrm{l}$ of RNase-free water (1\% DEPC). In addition, the mRNA samples from eggs, larvae, pupae and adult males were amplified using the MessageAmp III RNA amplification kit (Ambion, Austin, TX, USA), creating a sample that was cRNA.

\section{cDNA library preparation for $\mathbf{4 5 4}$ sequencing}

For each sample, a cDNA library was prepared with mRNA or cRNA using a cDNA rapid library preparation kit (Roche, Branford, CT, USA) according to the manufacturer's instructions, with minor changes. Briefly stated, $18 \mu \mathrm{l}$ of mRNA or cRNA (around $500 \mathrm{ng}$ ) were fragmented using fragmentation solution [0.1 M ZnCl $2,0.1 \mathrm{M}$ Tris-HCl (pH 7.0)], followed by vortex mixing and a brief centrifugation, and then heated at $70^{\circ} \mathrm{C}$ for $30 \mathrm{~s}$. The reaction was stopped by chilling on ice and adding $2 \mu \mathrm{l}$ of $0.5 \mathrm{M}$ EDTA (pH 8.0) and $28 \mu \mathrm{l}$ of $10 \mathrm{mM}$ Tris $\mathrm{HCl}(\mathrm{pH}$ 7.5). The mRNA fragments were purified using $80 \mu \mathrm{l}$ of RNA Clean reagent, containing SPRI beads (Beckman 
Coulter, Beverly, MA, USA), and $19 \mu \mathrm{l}$ of $10 \mathrm{mM}$ Tris $\mathrm{HCl}(\mathrm{pH}$ 7.5). The beads were removed with centrifugation, and the supernatant containing the RNA was added to a new $200 \mu$ l tube.

The first-strand cDNA was synthesized by adding $8 \mu \mathrm{l}$ 5× RT-buffer AMV, $4 \mu \mathrm{l} 0.1 \mathrm{M}$ DTT, $4 \mu \mathrm{l} 10$ mM dNTP, $1 \mu \mathrm{l}$ protector RNase inhibitor $(25 \mathrm{U} / \mu \mathrm{l}), 2 \mu \mathrm{l}$ AMV RT (25 $\mathrm{U} / \mu \mathrm{l})$ to the clean, fragmented RNA, gently mixing, then incubating at $25^{\circ} \mathrm{C}$ for $10 \mathrm{~min}$, followed by $42^{\circ} \mathrm{C}$ for $60 \mathrm{~min}$. The second strand cDNA was synthesized by mixing in $30 \mu \mathrm{l} 5 \times$ second strand synthesis buffer, $1.5 \mu \mathrm{l}$ $10 \mathrm{mM}$ dNTPs, $6.5 \mu \mathrm{l} 2^{\text {nd }}$ strand enzyme and $72 \mu \mathrm{l}$ double distilled water before incubating at $16^{\circ} \mathrm{C}$ for $2 \mathrm{~h}$, then adding $20 \mu \mathrm{l}$ T4 DNA polymerase, incubating at $16^{\circ} \mathrm{C}$ for $5 \mathrm{~min}$, and finally adding $17 \mu \mathrm{l}$ of $0.2 \mathrm{M}$ EDTA $(\mathrm{pH} 8.0)$ to stop the reaction. The double stranded cDNA was purified using AMPure beads (Beckman Coulter, Beverly, MA, USA), and the cDNA was then dissolved in $16 \mu \mathrm{l}$ of $10 \mathrm{mM}$ Tris- $\mathrm{HCl}(\mathrm{pH} 7.5)$. The cDNA was further purified using gel purification to isolate fragments of 500-800 bp.

To repair fragment ends, $9 \mu \mathrm{l}$ of end repair mix $(2.5 \mu \mathrm{l}$ RL (Rapid library) 10× buffer, $2.5 \mu \mathrm{l}$ RL ATP, $1.0 \mu \mathrm{l} \mathrm{RL}$ dNTP, $1.0 \mu \mathrm{l}$ RL T4 polymerase, 1.0 $\mu \mathrm{l}$ RL PNK and $1.0 \mu \mathrm{l}$ R Taq polymerase), from a cDNA RL preparation kit (Roche, Branford, CT, USA), were added to the cDNA, incubated at $25^{\circ} \mathrm{C}$ for $20 \mathrm{~min}, 72^{\circ} \mathrm{C}$ for $20 \mathrm{~min}$, and then held at $4^{\circ} \mathrm{C}$. The adaptor ligation was completed by adding $1 \mu \mathrm{l}$ of RL adaptor and $1 \mu \mathrm{l}$ of RL ligase to the reaction tube and incubating at $25^{\circ} \mathrm{C}$ for $10 \mathrm{~min}$. The small fragments (less than $100 \mathrm{bp}$ ) were removed using AMPure beads, and the supernatant contained the cDNA library. The cDNA libraries were then amplified by running emulsion-PCR and sequence analysis performed on a Roche GS-FLX system at the Center for Integrated BioSystems (CIB), Utah State University, Logan, Utah (http://biosystems.usu.edu/).

\section{Sequence assembly, annotation and detoxification gene identification}

The 454 sequence outputs were aligned and assembled de novo using CLC Genomics Workbench. The contigs and singletons obtained from de novo assemblies were BLAST-searched against the GenBank database at the National Center for Biotechnology Information (NCBI) (http://www.ncbi.nlm.nih.gov/BLAST/) in the iNquiry Bioinformatics Portal. Those similarities maintaining Evalues of less than or equal to 0.001 (more than 93\% of matches were based on $E \leq \mathrm{e}^{-05}$ ) were treated as significant matches and were selected as the annotation of $B$. huntii unigenes. The detoxification genes were identified by comparison with detoxification genes found in $A$. mellifera, D. melanogaster and other organisms.

\section{The quality measurement of RNA, cDNA and sequences assembly}

The quality and integrity of total RNA, mRNA and cDNA is very important for obtaining high quality transcriptome sequences. The concentration of total RNA was measured using a NanoDrop 2000 Spectrophotometer (Thermo Scientific, Inc. Wilmington, DE, USA), and the quality and integrity of total RNA was examined by electrophoresis. We only used total RNA samples with an $\mathrm{A}_{260} / \mathrm{A}_{280}$ ratio of 2.0 to 2.2 and two typical rRNA bands.

The mRNA concentrations were measured after the first purification from total RNA, and then again after fragmentation for cDNA preparation, using a spectrophotometer (Turner BioSystems, Inc. Sunnyvale, CA USA) with ribogreen RNA reagent (Invitrogen, Foster, CA, USA). The quality and integrity of the mRNA was examined using an Agilent 2100 Bioanalyzer with RNA 6000 Pico kit (Agilent Technologies, Santa Clara, CA, USA). All samples used were of high quality and integrity, as determined by mRNA fluorescence figure with typical shape of broad peak and without two ribosomal RNA contamination peaks. The quality of the fragmented mRNA were determined by running $1 \mu \mathrm{l}$ of the fragmented mRNA and $1 \mu \mathrm{l}$ of non-fragmented mRNA on an RNA 6000 Pico Chip on the Agilent 2100 Bioanalyzer. All fragmented samples showed lengths of around $800 \mathrm{bp}$.

The quality of the cDNA library was determined by the Center for Integrated BioSystems (CIB), Utah State University using a high sensitivity DNA assay on an Agilent Bioanalyzer. All samples displayed a broad shape of peak from $600 \mathrm{bp}$ to $1200 \mathrm{bp}$ with a relatively higher peak at approximately $800 \mathrm{bp}$. The total read count for the 454 sequence after assembly was 837,010 . The average read length was 425 bp with a total read length of $355,789,178$ bp.

\section{Gene diversity and expression levels for detoxification and stress related genes}

The diversities of detoxification genes were determined by identifying the number of genes in the particular enzyme group using a BLAST search against the GenBank database at NCBI. Assembled contigs from B. huntii that differed from each other in sequence, but matched the same gene in GenBank were considered to be different regions of the same gene if the contigs were each shorter than half the sequence length of the GenBank gene, otherwise they were considered to be different genes.

The expression levels of individual detoxification genes were estimated using RNA-seq $[67,68]$ as follows:

\footnotetext{
Expression level $=($ Total reads of the gene $)$

/ (Total mapped reads in millions for the sample $\times$ gene length in $\mathrm{Kb}$ )
} 
The cumulative expression level for a group of genes was calculated as follows:

Expression level $=($ Total reads within the group of genes $)$

/(Total mapped reads in millions for the sample $\times$ average length of the group of genes in $\mathrm{Kb}$ )

\section{Availability of supporting data}

The sequence data for $B$. huntii cited in this article can be found in the NCBI Sequence Read Archive (SRA), in study \#SRP016919, accessions SRX206116 through SRX206124 in. http://sra.dnanexus.com/studies/SRP016 919/experiments. The genomic data for A. mellifera, $B$. impatiens, B. terrestris, D. melanogaster, and $M$. rotundata are available at http://www.ncbi.nlm.nih.gov/genome.

\section{Additional file}

Additional file 1: Table S1. Detoxification and stress response related genes identified in Bombus huntii.

\section{Competing interests}

The authors have no competing interests to declare.

\section{Authors' contributions}

All authors were involved in planning, data interpretation, and writing the manuscript. In addition, JX isolated RNA, constructed the cDNA library, and performed the bioinformatics analysis including assembly of sequences, annotation of unigenes (contigs and singletons set), identification of detoxification genes; JS provided bumble bee samples from insect cultures; and RJ conceived the idea and provided conceptual oversight. All authors have read and approved the final manuscript.

\section{Acknowledgments}

We thank M. Berenbaum (University of Illinois at Urbana-Champaign) for reviewing a draft of this manuscript, and J. Knoblett for technical assistance in obtaining the bees. This work was funded by the USDA-ARS Pollinating Insects-Biology, Management and Systematics Research Unit, Logan, UT.

\section{Author details}

'Department of Biology, Utah State University, 1410 N 800 E, North Logan, UT 84341, USA. ²UDA-ARS, Pollinating Insects Research Unit, Department of Biology, Utah State University, Logan, UT 84322-5310, USA.

Received: 21 May 2013 Accepted: 6 December 2013

Published: 12 December 2013

\section{References}

1. David JP, Strode C, Vontas J, Nikou D, Vaughan A, Pignatelli PM, et al: The Anopheles gambiae detoxification chip: a highly specific microarray to study metabolic-based insecticide resistance in malaria vectors. Proc Natl Acad Sci USA 2005, 102:4080-4084.

2. Poupardin R, Reynaud S, Strode C, Ranson H, Vontas J, David JP: Crossinduction of detoxification genes by environmental xenobiotics and insecticides in the mosquito Aedes aegypti: impact on larval tolerance to chemical insecticides. Insect Biochem Molec 2008, 38:540-551.

3. Willoughby L, Chung H, Lumb C, Robin C, Batterham P, Daborn PJ: A comparison of Drosophila melanogaster detoxification gene induction response for six insecticides, caffeine and phenobarbital. Insect Biochem Molec 2006, 36:934-942.

4. Claudianos C, Ranson H, Johnson RM, Biswas S, Schuler S, Berenbaum MR, et al: A deficit of detoxification enzymes: pesticide sensitivity and environmental response in the honey bee. Insect Mol Biol 2006, 15:615-636.

5. Tribolium Genome Sequencing Consortium: The genome of the model beetle and pest Tribolium castaneum. Nature 2008, 452:949-955.
6. Bromenshenk JJ, Carlson SR, Simpson JC, Thomas JM: Pollution monitoring of Puget Sound with honey bees. Science 1985, 227:632-634.

7. Krupke $\mathrm{CH}$, Hunt Gl, Eitzer BD, Andino G, Given K: Multiple routes of pesticide exposure for honey bees living near agricultural fields. PLOS ONE 2012, 7:e29368

8. Cook D, Manson JS, Gardner DR, Welch KD, Irwin RE: Norditerpene alkaloid concentrations in tissues and floral rewards of larkspur and impacts on pollinators. Biochem System Ecol 2013, 48:123-131.

9. Corona M, Robinson GE: Genes of the antioxidant system of the honey bee: annotation and phylogeny. Insect Mol Biol 2006, 15:687-701.

10. Devillers J, Decourtye A, Budzinski H, Pham-Delegue MH, Cluzeau S, Maurin G: Comparative toxicity and hazards of pesticides to Apis and non-Apis bees. A chemometrical study. SAR QSAR Environ Res 2003, 14:389-403.

11. Misra JR, Horner MA, Lam G, Thummel CS: Transcriptional regulation of xenobiotic detoxification in Drosophila. Genes Dev 2011, 25:1796-1806.

12. Shen SK, Dowd PF: Detoxifying enzymes and insect symbionts. $J$ Chem Educ 1992, 69:796-799.

13. Johnson RM, Ellis MD, Mullen C, Frazier M: Pesticides and honey bee toxicity-USA. Apidologie 2010, 41:312-331.

14. Yang T, Liu N: Genome analysis of cytochrome P450s and their expression profiles in insecticide resistant mosquitoes: Culex quinquefasciatus. PLOS ONE 2011, 6:e29418.

15. Wen Z, Scott JG: Cytochrome P450 CYP6L1 is specifically expressed in the reproductive tissues of adult male German cockroaches, Blattella germanica (L.). Insect Biochem Molec 2011, 31:179-187.

16. Yang J, Yang C, Qiao C: Overexpression of protein disulfide isomerase Dsb A enhanced detoxification of organophosphates and enhanced detectability in the environment following degradation of pesticide residues. World J Microbiol Biotechnol 2011, 27:785-790.

17. Schröder $P$, Collins $C$ : Conjugating enzymes involved in xenobiotic metabolism of organic xenobiotics in plants. Int/ J Phytoremediat 2002, 4:247-265.

18. Kim BY, Hui WL, Lee KS, Wan H, Yoon HJ, Gui ZZ, et al: Molecular cloning and oxidative stress response of a sigma-class glutathione S-transferase of the bumblebee Bombus ignitus. Comp Biochem Phys B 2011, 158:83-89.

19. Kostaropoulos I, Papadopoulos Al, Metaxakis A, Boukouvala E, Papadopoulou-Mourkidou E: Glutathione S-transferase in the defence against pyrethroids in insects. Insect Biochem Molec 2001, 31:313-319.

20. Kostaropoulos I, Papadopoulos Al, Metaxakis A, Boukouvala E, Papadopoulou-Mourkidou E: The role of glutathione S-transferase in the detoxification of some organophosphorus insecticides in larvae and pupae of the yellow mealworm, Tenebrio molitor (Coleoptera: Tenebrionidae). Pest Manag Sci 2001, 57:501-508.

21. Enayati AA, Ranson H, Hemmingway J: Insect glutathione transferases and insecticide resistance. Insect Mol Biol 2005, 14:3-8.

22. Heidari R, Devonshire AL, Campbell BE, Dorrian SJ, Oakeshott JG, Russell RJ: Hydrolysis of pyrethroids by carboxylesterases from Lucilia cuprina and Drosophila melanogaster with active sites modified by in vitro mutagenesis. Insect Biochem Molec 2005, 35:597-609.

23. Cook JM: Sex determination in the Hymenoptera: a review of models and evidence. Heredity 1993, 71:421-435.

24. Kearns CA, Thomson JD: Natural history of bumble bees: a sourcebook for investigations. Boulder: Univ Press Colorado; 2001.

25. Leal JFM, Barbancho M: Acetaldehyde detoxification mechanisms in Drosophila melanogaster adults involving aldehyde dehydrogenase (ALDH) and alcohol dehydrogenase (ADH) enzymes. Insect Biochem Molec 1992, 22:885-892.

26. DeJong RJ, Miller LM, Molina-Cruz A, Gupta L, Kumar S, Barillas-Mury C Reactive oxygen species detoxification by catalase is a major determinant of fecundity in the mosquito Anopheles gambiae. Proc Natl Acad Sci USA 2007, 104:2121-2126.

27. Chung H, Sztal T, Pasricha S, Sridhar M, Batterham P, Daborn PJ: Characterization of Drosophila melanogaster cytochrome P450 genes. Proc Natl Acad Sci USA 2009, 106:5731-5736.

28. Sehlmeyer S, Wang L, Langel D, Heckel DG, Mohagheghi H, Petschenka G, et al: Flavin-dependent monooxygenases as a detoxification mechanism in insects: new insights from the arctiids (Lepidoptera). PLoS ONE 2010, 5:e10435.

29. Sallabhan $R$, Kerdwong J, Dubbs JM, Somsongkul D, Whangsuk W, Piewtongon $P$, et al: The hdhA gene encodes a haloacid dehalogenase that is regulated by the LyseR-Type regulator, HdhR, in Sinorhizobium meliloti. Mol Biotechnol 2013, 54:148-157. 
30. Marcaccia S, Ravetonb M, Ravenelb P, Schwitzguébela JP: The possible role of hydroxylation in the detoxification of atrazine in mature vetiver (Chrysopodon zizanioides Nash) grown in hydroponics. Z Naturforsch 2005, 60:427-434.

31. Cai QN, Han Y, Cao YZ, Hu Y, Zhao X, Bi JL: Detoxification of gramine by the cereal aphid Sitobion avenae. J Chem Ecol 2009, 35:320-325.

32. Molina-Cruz A, DeJong RJ, Charles B, Gupta L, Kumar S, Jaramillo-Gutierrez $\mathrm{G}$, et al: Reactive oxygen species modulate Anopheles gamiae immunity against bacteria and Plasmodium. J Biol Chem 2008, 283:3217-3223.

33. Halliwell B: Reactive species and antioxidants: redox biology is a fundamental theme of aerobic life. Plant Physiol 2006, 141:312-322.

34. Peiren N, de Graaf DC, Vanrobaeys F, Danneels EL, Devreese B, Van Beeumen J, et al: Proteomic analysis of the honey bee worker venom gland focusing on the mechanisms of protection against tissue damage. Toxicon 2008, 52:72-83.

35. Luikenhuis S, Perrone G, Dawes IW, Grant CM: The yeast Saccharomyces cerevisiae contains two glutaredoxin genes that are required for protection against reactive oxygen species. Mol Biol Cell 1998, 9:1081-1091.

36. Winter HR, Unadkat JD: Identification of cytochrome P450 and arylamine $\mathrm{N}$-acetyltransferase isoforms involved in sulfadiazine metabolism. Drug Metab Dispos 2005, 33:969-976.

37. Kubiak X, Dervins-Ravault D, Pluvinage B, Chaffotte AF, Gomez-Valero L, Dairou J, et al: Characterization of an acetyltransferase that detoxifies aromatic chemicals in Legionella pneumophila. Biochem J 2012, 445:219-228.

38. Cardenas CLL, Bourgine J, Cauffiez C, Allorge D, Lo-Guidice JM, Broly F, et al: Genetic polymorphisms of glycine N-acyltransferase (GLYAT) in a French caucasian population. Xenobiotica 2010, 40:853-861.

39. Fleck CB, Brock M: Characterization of an acyl-CoA: carobylate CoA-transferase from Aspergillus nidulans involved in propionyl-CoA detoxification. Molec Microbiol 2008, 68:642-656.

40. Marx CJ, Miller JA, Chistoserdova L, Lidstrom ME: Multiple formaldehyde oxidation/detoxification pathways in Burkholderia fungorum LB400. J Bacteriol 2004, 186:2173-2178

41. Quin G, Jia M, Liu T, Zhang X, Guo Y, Zhu K, et al: Heterologous expression and characterization of a sigma glutathione $S$-transferase involved in carbaryl detoxification from oriental migratory locust, Locusta migratoria manilensis (Meyen). J Insect Physiol 2012, 58:220-227.

42. Huang LF, Su B, Jao SC, Liu KT, Li WS: Aminopeptidase P mediated detoxification of organophosphonate analogues of sarin: mechanistic and stereochemical study at the phosphorus atom of the substrate. ChemBioChem 2006, 7:506-514.

43. Jancova P, Anzenbacker P, Anzenbacherova E: Phase II drug metabolizing enzymes. Biomed Pap MEd Facul Univ Palacky Olomouc Chech Repub 2010, 154:103-116.

44. Terriere LC: Induction of detoxification enzymes in insects. Ann Rev Entomol 1984, 29:71-88.

45. Han Q, Li J: Comparative characterization of Aedes 3-hydroxykynurenine transaminase/alanine glyoxylate transaminase and Drosophila serine pyruvate aminotransferase. FEBS Letters 2002, 527:199-204.

46. Amirmohammadi F, Sendi JJ, Zibaee A: Toxicity and physiological effects of essential oil of Artemisia annua (Labiatae) on Agriolimax agrestis L. (Stylommatophoa: Limacidae). J Plant Protect Res 2012, 52:185-189.

47. Bates JM, Akerlund J, Mittge E, Guillemin K: Intestinal alkaline phosphatase detoxifies lipopolysaccharide and prevents inflammation in response to the gut microbiota. Cell Host Microbe 2007, 2:371-382.

48. Dowd PF: Insect fungal symbionts: a promising source of detoxifying enzymes. J Indust Microbiol 1992, 9:149-161.

49. Shitomi Y, Hayakawa T, Hossain DM, Higuchi M, Miyamoto K, Nakanishi K, et al: A novel $96-\mathrm{kDa}$ aminopeptidase localized on epithelial cell membranes of Bombyx mori midgut, which binds to Cry1 Ac toxin of Bacillus thuringiensis. J Biochem 2006, 139:223-233.

50. Chandran NS, Vunnava P, Wu Y, Kapatos G: Specificity proteins Sp1 and $\mathrm{Sp} 3$ interact with the rat GTP cyclohyrolase I proximal promoter to regulate transcription. J Neurochem 2008, 104:1233-1248.

51. Reszka E, Chung KR, Tekauz A, Malkus A, Arseniuk E, Krupinsky JM, et al: Presence of $\beta$-glucosidase (bg/1) gene in Phaeosphaeria nodorum and Phaeosphaeria avenaria f.sp. triticea. Can J Botany 2005, 83:1001-1014.

52. Bork P, Koonin EV: A new family of carbon-nitrogen hydrolases. Protein Sci 1994, 3:1344-1346.

53. McLoughlin SY, Jackson C, Liu JW, Ollis DL: Growth of Escherichia coli coexpressing phosphotriesterase and glycerophosphodiester phosphodiesterase, using paraoxon as the sole phosphorus source. Appl Environm Microbiol 2004, 70:404-412.

54. Ahmed S, Saleem MA, Shahzad RK: Effect of cypermethrin (10 EC) and bifenthrin (10 EC) on levels of acid and alkaline phosphatases in a strain of Tribolium castaneum (Herbst) (Coleoptera: Tenebrionidae). Pakistani Entomol 2004, 26:47-52.

55. Yang $Y$, Chen $H, W u$ Y, Yang $Y$, Wu S: Mutated cadherin alleles from a field population of Helicoverpa armigera confer resistance to Bacillus thuringiensis toxin Cry1Ac. Appl Environm Microbiol 2007, 73:6939-6944.

56. Lee SM, Lee SB, Park CH, Choi J: Expression of heat shock protein and hemoglobin genes in Chironomus tentans (Diptera, Chironomidae) larvae exposed to various environmental pollutants: a potential biomarker of freshwater monitoring. Chemosphere 2006, 65:1074-1081.

57. Zagrobelny M, Bak S, Rasmussen AV, Jørgensen B, Naumann CM, Møller BL: Cyanogenic glucosides and plant-insect interactions. Phytochemistry 2004, 65:293-306.

58. Borges AA, Humann FC, Tavares MG, Campos LAO, Hartfelder K: Gene copy number and differential gene expression in haploid and diploid males of the stingless bee, Melipona quadrifasciata. Insect Soc 2012, 59:587-598.

59. Detzel A, Wink M: Attraction, deterrence or intoxication of bees (Apis mellifera) by plant allelochemicals. Chemoecology 1993, 4:8-18.

60. Bainbridge S, Bownes M: Ecdysteroid titer during Drosophila development. Biochem 1988, 18:185-197.

61. Buckner JS, Kemp WP, Bosch J: Characterization of the triacylglycerols from overwintering prepupae of the alfalfa pollinator Megachile rotundata (Hymenoptera: Megachilidae). Arch Insect Biochem Physiol 2004, 57:1-14.

62. Robinson FA, Nation JL: Long-chain fatty acids in honeybees in relation to sex, caste, and food during development. J Apicul Res 1970, 9:121-127.

63. Kostaropoulos I, Mantzari AE, Papadopoulos Al: Alterations of some glutathione S-transferase characteristics during the development of Tenebrio molitor (Insecta: Coleoptera). Insect Biochem Molec 1996, 26:963-969.

64. Mao W, Schuler MA, Berenbaum MR: Honey constituents up-regulate detoxifcation and immunity genes in the western honey bee Apis mellifera. Proc Natl Acad Sci USA 2013. doi: 0.1073/pnas.1303884110.

65. Adler LS, Irwin RE: Ecological costs and benefits of defenses in nectar. Ecology 2005, 86:2968-2978.

66. Strange JP: Nest initiation in three North American bumble bees (Bombus): gyne number and presence of honey bee workers influence establishment success and colony size. J Insect Science 2010, 10:1-11.

67. Mortazavi A, Williams BA, McCue K, Schaeffer L, Wold B: Mapping and quantifying mammalian transcriptomes by RNA-Seq. Nature Methods 2008, 5:621-628.

68. Wilhelm BT, Landry JR: RNA-Seq-quantitative measurement of expression through passively parallel RNA-sequencing. Methods 2009, 48:249-257.

\section{doi:10.1186/1471-2164-14-874}

Cite this article as: Xu et al:: Detoxification and stress response genes expressed in a western North American bumble bee, Bombus huntii (Hymenoptera: Apidae). BMC Genomics 2013 14:874.

\section{Submit your next manuscript to BioMed Central and take full advantage of:}

- Convenient online submission

- Thorough peer review

- No space constraints or color figure charges

- Immediate publication on acceptance

- Inclusion in PubMed, CAS, Scopus and Google Scholar

- Research which is freely available for redistribution 